\title{
A PESQUISA DE CONTEÚDOS NA WEB: CO-PARTILHANDO IDÉIAS ENTRE A CIÊNCIA DA INFORMAÇÃO E A EDUCAÇÃO
}

\author{
Maria Auxiliadora Padilha \\ Doutora em Educação pela Universidade Federal de Pernambuco \\ Professora do Programa de Pós-Graduação em Educação Matemática e Tecnológica da UFPE. \\ dora padilha@hotmail.com
}

\begin{abstract}
Resumo
Este artigo traz um debate sobre a pesquisa de conteúdos entre a Ciência da Informação e a Educação, no contexto de uma sociedade marcada pelas Tecnologias da Informação e Comunicação, principalmente a internet, e que estão cada vez mais integrando os artefatos tecnológicos do ambiente escolar. Nesse sentido, este trabalho apresenta uma proposta metodológica de pesquisa de conteúdos na web, que pode ser utilizada no Ensino Fundamental, Médio e Superior, respeitando os contextos e limites de cada nível de ensino. A proposta ora apresentada compreende habilidades que precisam ser mobilizadas pelos alunos, no processo de pesquisa, e princípios que devem reger a pesquisa numa perspectiva de educação baseada na construção do conhecimento em detrimento do simples acúmulo de informações.
\end{abstract}

Palavras-Chave: Pesquisa de conteúdos na web. Tecnologias da Informação e Comunicação. Construção do Conhecimento.

\section{INTRODUÇÃO}

Este artigo tem como objetivo discutir a pesquisa escolar ou pesquisa de conteúdos, no contexto de uma sociedade marcada pela introdução das Tecnologias da Informação e Comunicação (TICs), principalmente a Internet, e por uma educação escolar ainda em fase de acolhimento e compreensão das reais possibilidades pedagógicas desses recursos tecnológicos no âmbito educacional.

A'pesquisa escolar' ou 'pesquisa de conteúdos' é uma estratégia didática muito utilizada por professores em suas práticas de ensino e por alunos para realização de suas atividades educativas, seja no Ensino Fundamental e Médio, seja no Ensino Superior. Entretanto, apesar de sua constante

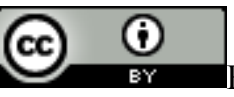

Esta obra está licenciada sob uma Licença Creative Commons. DOI 10.5007/1518-2924.2009v14n28p115 
utilização nos processos de ensino e de aprendizagem, este fenômeno é pouco estudado no campo da educação (MORAES et al, 2004), sendo mais discutido na área de Ciência da Informação (CAMPELLO, 2002; CARVALHO, 2002; BELLUZZO, 2005; FRAGOSO e BLATTMANN, 2003; MORO et al, 2006), embora não deixe de suscitar debates calorosos entre docentes e discentes quando diante de discussões sobre sua importância e sua prática.

Utilizaremos, daqui por diante, para nos referirmos a este tipo de situação didática, a denominação de 'pesquisa de conteúdos'. Chamamos 'Pesquisa de Conteúdos' tanto para o Ensino Fundamental como para o Ensino Superior, visto que nos dois espaços há o trabalho com conteúdos. Embora a proposta metodológica de 'pesquisa na web' apresentada tenha sido desenvolvida no âmbito do Ensino Superior, ela também pode ser realizada nos níveis de Ensino Fundamental e Médio, considerando que as habilidades e princípios mobilizados com a pesquisa para a construção do conhecimento pelo aluno são da mesma forma, mobilizados nos estudantes desses níveis de ensino, considerando, é claro, o contexto e níveis adequados.

Além disso, estamos falando sobre a produção do conhecimento próprio do sujeito, portanto, de acordo com a teoria dos esquemas cognitivos, desde que nascemos estamos construindo nossa representação da realidade, que vai se ampliando e complexificando à medida que nos formamos (CARVALHO, 1998).

Aliado ao fato da pesquisa escolar ou de conteúdos, enquanto metodologia de ensino tradicional, ser um objeto de estudo pouco investigado, com a introdução das TICs nas salas de aula e disponíveis na sociedade em geral, principalmente ao alcance dos alunos e alunas, este procedimento de ensino e estudo apresenta uma nova perspectiva, principalmente no que se refere à prática docente e às metodologias de ensino derivadas dessa junção: pesquisa escolar + TICs.

\section{A PESQUISA ESCOLAR NO ENSINO FUNDAMENTAL: 'O QUE É, COMO É QUE SE} FAZ'?

Acreditamos que os alunos não sabem fazer pesquisa por causa do tipo de orientação que eles recebem (ou não) de seus professores. Segundo Silva (1995) os alunos, em todos os níveis de ensino, do fundamental à pós-graduação, não são orientados a usar a biblioteca de forma racional. Isto inclui desde a escolha dos livros a serem pesquisados, que geralmente é apenas um, indicado 
pelo professor, até o tratamento das informações coletadas na pesquisa, que quase sempre não é feito.

Moro et $\mathrm{al}^{1}$ ( $\left.\mathrm{s} / \mathrm{d}\right)$ identificam a pesquisa escolar "como uma atividade sistematizada, um processo formal, que visa encontrar respostas para questões propostas pelo professor ou pela própria turma" e que os alunos devem ter alguns conhecimentos de pesquisa científica para realização de sua pesquisa escolar. As autoras identificam como procedimentos necessários de serem informados aos alunos pelos seus professores quando solicitarem uma pesquisa: "o que, de que trata o trabalho, para que será realizado, quanto (dimensão), quando (prazo para entrega), onde o assunto pode ser encontrado e como forma da comunicação do trabalho".

\begin{abstract}
A pesquisa escolar deve ser uma atividade em que os alunos tenham oportunidade de estudo independente, de planejamento de trabalho, de uso de fontes de informação, de desenvolver o pensamento crítico, de adquirir autonomia no processo de conhecimento, de aprender a trabalhar com seus colegas colaborando e contribuindo com o grupo, de sugerir, construir, elaborar, concluir, sentindo-se satisfeito com os resultados atingidos (MORO et al, op cit).
\end{abstract}

Com a chegada da rede mundial de computadores na escola, a Internet, as fontes de informação e comunicação se amplificaram, a "rede" possibilita tanto a comunicação como o acesso a informações através de uma gama de formas textuais que intensificam a dinamicidade das relações entre as pessoas em qualquer lugar do mundo e também as construções individuais dos sujeitos. Contudo, também ficou muito mais fácil, para quem possui condições de acessar informações, copiar, colar, imprimir, reproduzir. Dessa forma, a possibilidade de uma construção de saberes a partir de uma coleta e tratamento de dados se tornou mais difícil. Ou seja, há muito mais informações disponíveis para que o aluno possa pesquisar, porém, os seus resultados ficaram mais comprometidos, pois agora os alunos nem sequer lêem ou digitam as cópias, apenas copiam-colam ou imprimem direto do site. Também é possível encontrar sites que disponibilizam trabalhos completos sobre qualquer tema ou conteúdo. Além disso, a própria estrutura não-linear da $W e b$, diferente dos ambientes e materiais estruturados e simplificados que nossos alunos estão acostumados, dificulta a busca e seleção de informações relevantes e a organização de um pensamento complexo e articulado por parte dos alunos de forma que ele realize uma concatenação de idéias e argumentações próprias.

\footnotetext{
${ }^{1}$ Disponível em http://www.eci.ufmg.br/gebe/downloads/304.pdf.
} 
É necessário enfatizar que no momento atual de explosão informacional em que vivemos, possuir competências de pesquisa, análise e reconstrução de saberes é imprescindível para qualquer cidadão. E pelo que vimos até agora, a escola e os professores ainda não estão preparados para atuarem efetivamente na orientação de seus alunos, para a realização de uma pesquisa de conteúdos que produza conhecimentos significativos, de forma crítica e criativa. Urge, então, uma reflexão mais propositiva que estabeleça condições concretas de modificação dessa realidade.

Uma importante contribuição sobre a pesquisa em sala de aula como princípio educativo e que também fundamenta este estudo é a produção do grupo de pesquisadores da Pontifícia Universidade Católica do Rio Grande do Sul, liderados pelo Professor Doutor Roque Moraes, que tratam da temática. Para Moraes et al (2004)

\begin{abstract}
A pesquisa em sala de aula pode ser compreendida como um movimento dialético, em espiral, que se inicia com o questionamento dos estados do ser, fazer e conhecer dos participantes, construindo-se a partir disso novos argumentos que possibilitam atingir novos patamares desse ser, fazer e conhecer, estágios esses comunicados a todos os participantes do processo (MORAES et al, 2004, p. 11).
\end{abstract}

Dessa forma, os autores apresentam o questionamento, a construção de argumentos e a comunicação como os três momentos e princípios de uma pesquisa que desenvolva a transformação da sala de aula em um espaço de permanente entendimento da realidade a partir de verdades provisórias que devem sempre ser questionadas e superadas.

Para Barreiro (2004) o questionamento sistemático é o alicerce sobre o qual se erige a pesquisa na sala de aula como princípio educativo. Esse questionamento, entretanto, deve possuir algumas características. Primeiro, ele só se justifica enquanto postura investigativa. Segundo, deve ser produtivo, "no sentido de representar avanço em termos de domínio, visão global e informação" (p. 175). Dessa forma, as características do questionamento estão relacionadas à produção, argumentação, coerência e responsabilidade para a formação das qualidades formal e política do estudante, do professor e, inclusive, do próprio conhecimento.

Ramos (2004) discute a necessidade do princípio ético na argumentação, de forma que esta esteja sempre presente na sala de aula, para a formação de sujeitos críticos, propositivos e ativos na sociedade contemporânea. Para ele, a argumentação é imprescindível para a manutenção da democracia, pela sua capacidade de resolução de problemas. "Para participarem de tomadas de decisões, no plano social, os sujeitos devem estar capacitados para elaborar, selecionar e emitir 
argumentos consistentes" (p. 31). É papel social da escola atual, portanto, formar os alunos para a competência argumentativa.

Para Moraes et al (2004) é necessário que as verdades provisórias construídas a partir do questionamento e da argumentação sejam "debatidas, criticadas, para tornarem-se cada vez mais fortes nos argumentos que as constituem” (p. 18/19), culminando, portanto, no último princípio destacado pelos autores, a comunicação. Esta acontece a partir de dois momentos integrados e superpostos. O primeiro momento refere-se ao esforço de tornar os argumentos claros e expressos em escrita ou oralidade. O segundo momento é a divulgação propriamente dita, exposta à crítica.

Mas como as Tecnologias da Informação e Comunicação estão sendo apropriadas nessa proposta de pesquisa enquanto princípio educativo? Para Moraes et al (2004) a Internet contribui para a pesquisa em sala de aula, pois os estudantes podem ter acesso a variedade de informações que auxiliam a "levantar questões, procurar respostas, solucionar problemas propostos e interagir uns com os outros" (p. 89). A autora argumenta que a Internet pode ser usada nos três momentos do ciclo dialético proposto por Moraes et al (2004).

Entendemos que, através da busca e recuperação de informações, o estudante terá em suas mãos um referencial teórico bastante forte para o questionamento e construção de seus argumentos. Já os serviços para a troca de idéias e informações num grupo de pessoas e entre grupos é bastante útil para a comunicação e crítica dos argumentos construídos (MORAES et al, 2004, p. 89).

Entretanto, nos perguntamos qual a especificidade da Web para a pesquisa de conteúdos? Como os professores podem utilizá-la, a partir de suas características, como recurso para a construção de conhecimentos pelo aluno e que tipo de orientação deve ser proposta para a realização de uma pesquisa de conteúdos significativa? Nosso estudo se propõe a responder essa indagação.

\section{A BIBLIOTECA ESCOLAR E VIRTUAL: ESPAÇOS DE CONSTRUÇÃO DE CONHECIMENTOS}

A maior parte dos estudos sobre pesquisa de conteúdos que encontramos tem como contexto de estudo o nível fundamental de ensino e são da área de Ciência da Informação. Consideramos que é necessário um esforço conjunto entre professores e cientistas da informação, ou bibliotecários para 
procurar compreender as possibilidades da Web e suas especificidades relativas às formas de aprender com as TICs e, conseqüentemente, buscar estratégias de ensino que considerem a complexidade das situações de aprendizagem que delas decorrem. Por isso, é importante ressaltar as contribuições da área de Ciência da Informação para esta temática, visto que essa aproximação e intercâmbio de conhecimentos são necessários para a formulação de uma construção complexa da literatura sobre o tema. Sendo assim, discutiremos a seguir a contribuição da área para esse debate. Belluzzo (2005) relaciona a evolução tecnológica à uma nova prática de uso das bibliotecas por conta da profusão de informações disponibilizadas pelas TICs. Entretanto, segundo a autora, esse potencial não está sendo bem aproveitado devido a aspectos financeiros, mas, principalmente, pelo despreparo das pessoas frente à complexidade da utilização adequada das fontes eletrônicas de informações que exigem "uma maior reflexão crítica sobre sua pertinência, relevância e confiabilidade" (BELLUZZO, 2005, p. 04). Portanto, apesar da Internet potencializar uma construção de conhecimentos sistêmica e complexa (PELLANDA, 2005), isso não acontece instintivamente, sem uma orientação e formação para tal.

Belluzzo (2005) ainda define biblioteca virtual como uma biblioteca que possui as mesmas características das tradicionais ou concretas, mas que não tem existência física e sua oferta é ampliada, em geral para os recursos e serviços de formação e orientação (op cit, pp. 04/05). A autora refere-se à constatação de Lévy (1999) sobre a mutação contemporânea da relação com o saber, onde ó ciberespaço suporta tecnologias intelectuais que modificam diversas funções cognitivas do ser humano.

A educação deve garantir, para a autora, o "acesso às fontes de informação, estímulo ao trabalho intelectual, à mobilização das fronteiras próprias e coletivas do saber, colocando-o em circulação e incorporando-o à geração de novo conhecimento" (BELLUZZO, 2005, p. 06). As pessoas devem ser formadas, então, para, ao final de sua escolarização formal, saberem tratar as informações adequadamente, tornando o estudante um criador de discurso e não apenas um ouvinte passivo. Entretanto, a escola, tradicionalmente, tem investido em uma formação passiva, e a pesquisa escolar é o reflexo desse tipo de formação, quando o aluno não é orientado a tratar as informações coletadas, mas apenas a repetir o que o professor quer ouvir, numa clara intenção de acúmulo de informações ao invés do tratamento destas para uma reelaboração própria. Os princípios fundamentais da pesquisa escolar, segundo Belluzzo (2005) são

auxiliar as pessoas a estudar com independência, planejar, conviver e interagir em grupo, conhecer e aceitar as opiniões dos outros, usar adequadamente os recursos informacionais 
tais como bibliotecas e outras fontes de consulta, desenvolver o pensamento crítico e o gosto pela leitura, adquirir autonomia no processo de conhecimento, aprender a trabalhar de forma colaborativa e em rede, entre outros (p. 08).

Bruce (apud BELLUZZO, 2005) afirma que as pessoas devem possuir certas habilidades para o manejo adequado da informação. Aprender a usar as TICs para interagir com outras pessoas e comunidades, conhecer e utilizar as fontes de informação, usar estrategicamente as informações obtidas em outras situações, saber armazenar e recuperar as informações quando for necessário, construir conhecimentos e soluções criativas a partir das informações e utilizá-los para benefício próprio e coletivo.

Tanto os princípios definidos por Belluzzo (2005) como as habilidades discutidas por Bruce (apud BELLUZZO, 2005), indicam para algo além da acumulação, assimilação e transmissão de informações.

Identificar habilidades, entretanto, é relativamente fácil, mais difícil é orientar os alunos de forma a que eles percebam a necessidade dessas habilidades e saibam mobilizá-las de forma consciente e adequada. É necessário, portanto, que o professor oriente os estudantes a compreenderem suas habilidades cognitivas e saberem organizar seu pensamento, seu estudo e, conseqüentemente, a produção de seus próprios saberes.

Quanto à necessidade de compreender melhor essas habilidades, Xavier (2005), ao discutir o hipertexto, afirma que diversas pesquisas mostram

\begin{abstract}
a necessidade dos internautas reajustarem as suas estratégias de leitura em função das especificidades de formatação textual propostas pelo hipertexto, para só assim começarem a tirar proveito dessa nova sistemática de organização e acesso à informação. O problema maior que eles levantam consensualmente é a inexistência, no momento, de um modelo teórico para dar conta do processamento cognitivo quando a leitura é feita no hipertexto (p. 174).
\end{abstract}

Além da distinção do tipo de material utilizado no processo de pesquisa, que Xavier (2005) trata especificamente dos hipertextos, os usuários também têm que possuir a compreensão do ambiente como um todo. Baseada no conceito de competência de Perrenoud, onde competência é "uma capacidade de agir eficazmente em um tipo de situação, capacidade que se apóia em conhecimentos, mas não se reduz a eles" (apud BELLUZZO, 2005, p. 10), Belluzzo afirma ser a competência, um conjunto de duas dimensões

a primeira, um domínio de saberes e habilidades de diversas naturezas que permite a intervenção prática na realidade e, a segunda, uma visão crítica do alcance das ações e o 
compromisso com as necessidades mais concretas que emergem e caracterizam o atual contexto social (p. 11).

Fundamentada nessa concepção de competência em dupla dimensão, a área de Biblioteconomia e Ciência da Informação discutem o conceito de Competência da Informação, que se constitui em "um processo contínuo de interação e internalização de fundamentos conceituais, atitudinais e de habilidades específicas" (BELLUZZO, 2005, p. 12), que servem de subsídio para a compreensão da informação e geração de novos conhecimentos que estejam a serviço das pessoas ao longo de sua vida.

Campello (2002) informa que a competência informacional ou information literacy surgiu nos Estados Unidos e foi usada, a princípio, para indicar habilidades para lidar com computadores e redes eletrônicas. Atualmente, “o termo designa, de forma ampla, o conjunto de habilidades necessárias para localizar, interpretar, analisar, sintetizar, avaliar e comunicar informação, esteja ela em fontes impressas ou eletrônicas" (p. 09/10).

Carvalho (2002), em sua pesquisa sobre o uso da Internet para pesquisas escolares por alunos do Ensino Fundamental em uma escola da rede particular em Belo Horizonte, conclui que a escola ainda não incorporou definitivamente a Internet como instrumento de aprendizagem, embora ela esteja presente na escola e nas casas dos alunos. Nesse estudo, 45\% dos alunos afirmaram que copiam os textos da Internet, confirmando a falta de preparo dos alunos em 'tratar' as informações e traduzi-las em seu próprio conhecimento. Carvalho ( op cit) não informou a quantidade exata, mas disse que quase a metade faz um resumo das informações que coleta. Ou seja, entre cópia e resumo, a quase totalidade fica na reprodução das informações.

Carvalho conclui que é importante que os professores desenvolvam em seus alunos as habilidades de "ler, interpretar, resumir, parafrasear, que são a base para a aprendizagem significativa" (p 36).

Podemos ver que desenvolver habilidades é a proposta e indicação dos estudiosos sobre a pesquisa escolar. $\mathrm{O}$ tratamento das informações é um dos mais indicados procedimentos que são sugeridos para uma pesquisa de conteúdos significativa. Mas, o que significa 'tratar a informação'? Como se 'constrói significados'? Como se 'reflete criticamente'? Essas são orientações que nós, professores, oferecemos aos nossos alunos quando estabelecemos uma pesquisa como trabalho de casa. Mas os alunos foram acostumados a repetir o que o professor diz, copiar os apontamentos dos livros e, no máximo, escrever com suas próprias palavras. Que tipo de tratamento queremos de nossos alunos?

A Ciência da Informação está fazendo sua parte procurando estratégias de articulação entre os bibliotecários e os professores. Cabe aos professores fazerem a sua parte. Aproveitar o potencial 
informacional das TICs, os espaços de aprendizagem proporcionados pelas bibliotecas, seja presencial ou virtual, e orientar devidamente seus alunos sobre o que significa cada solicitação sua. Tratar informação significa ler, verificar os conhecimentos que possui, os que não possui, relacionar, comparar, atribuir significados, valores, sob uma visão fundamentada e não apenas opinativa. Elaborar seu próprio conhecimento significa reestruturar as informações obtidas a partir de uma nova visão, a sua. Construir argumentos que dêem suporte às suas opiniões, conclusões, proposições. Conhecimento significa, principalmente, aplicação. Propor e verificar formas de aplicabilidade dos conhecimentos construídos. Ou seja, é necessário criar uma nova cultura escolar, uma nova forma de aprender, uma nova maneira de ensinar.

\section{PESQUISA DE CONTEÚDOS EM SITES}

Compreendendo a Internet como um grande banco de dados a disposição de quem pode ter acesso, verifica-se que qualquer endereço de entrada pública na Rede pode servir de subsídio para uma pesquisa de conteúdos. O site de um partido político, de uma prefeitura, de uma agência bancária e até mesmo um site pessoal podem fornecer informações ao usuário internauta, dependendo da natureza e objetivos da pesquisa.

Contudo, assim que a rede das redes firmou-se como um dos principais veículos de informação, diversas entidades e pessoas passaram a explorar esse potencial para abrigar, num mesmo local, informações e dados que servissem, especificamente, de fonte para a pesquisa escolar.

Aqui apresentamos alguns tipos de sites de pesquisa que se diferenciam dos demais por conta de seu objetivo explícito e específico de subsidiar pesquisas e trabalhos escolares e acadêmicos. Identificamos dois tipos de classificação, lembrando que não estamos esgotando as possibilidades de classificação da $W e b$, justamente por sua superestrutura diversificada e complexa:

\subsection{Classificação por conteúdo:}

a) Sites de áreas específicas - referem-se a uma única área do conhecimento, como língua portuguesa, arte, biologia, etc. 
b) Sites gerais - apresentam diversas áreas do conhecimento. Geralmente, na home-page há um menu principal com uma lista de links para as páginas das diversas áreas.

c) Portais gerais - estes portais são bastante diversificados, além dos conteúdos das diversas áreas do conhecimento, também podem apresentar notícias, informações gerais, guias de profissões, universidades, testes e outros serviços que vão além da pesquisa escolar.

d) Portais de pesquisa acadêmica - sites específicos para pesquisa acadêmica, que podem ser domínios de universidades, instituições de pesquisa, governamentais. O uso desses portais já está bastante difundido na área acadêmica, necessitando, entretanto, de maior ampliação das informações disponíveis. Um exemplo de uso disseminado da internet como fonte de informação acadêmica é o acesso a periódicos científicos digitais. As bases referenciais disponibilizadas pelo portal da Capes tiveram 4,6 milhões de acessos entre janeiro e maio de 2006. O periódico é o canal de comunicação científico mais importante desde o seu surgimento, em 1665, até hoje. A versão digital não difere em nada da versão impressa. A legitimidade do periódico é indiscutível, mesmo que tenha sido criado no formato eletrônico. Se a entidade que o publica tem boa reputação no meio acadêmico, e se tem um comitê científico, ele pode ser utilizado como fonte na pesquisa. ${ }^{2}$

e) Portais de busca acadêmica: atualmente os portais de busca geral estão investindo em domínios específicos para a busca acadêmica, como o google, o yahoo, etc.

\subsection{Classificação por usuário:}

a) Sites destinados apenas a alunos;

b) Sites com conteúdos apenas para professores;

c) Sites com conteúdos para alunos e professores;

d) Sites que incluem informações e serviços para os pais, curiosos, interessados, além dos professores e alunos.

Com todo potencial informacional que pode ser explorado tanto como metodologia de ensino como de estudo, a Internet pouco tem servido de referencial para professores quando indicam uma pesquisa escolar para seus alunos. Campello et al (2002) apresentam em sua pesquisa que apenas $4 \%$ das sugestões de sites que os alunos obtiveram para realizar uma pesquisa escolar foram de seus professores. A maior parte, $47 \%$, foi sugestão de amigos, pais, irmãos. Televisão, links da própria rede, jornais e revistas, contribuem para $40,6 \%$ das indicações. Outro dado importante é que apenas

\footnotetext{
${ }^{2}$ http://www.universiabrasil.net/materia/materia.jsp?materia $=12436$
} 
$25 \%$ dos alunos afirmam fazer pesquisa na escola. Os demais realizam suas explorações em casa, na casa de amigos ou parentes, no trabalho dos pais, etc. (CAMPELLO et al, 2002).

Para as pesquisas no Ensino Superior, alunos e professores podem contar com bibliotecas virtuais específicas para cada área ou de universidades e faculdades, além de sites de instituições de desenvolvimento, divulgação e fomento de pesquisa. Entretanto, os ambientes físicos para pesquisa nas universidades e faculdades ainda são precários, salvo algumas raras exceções.

A quantidade e variedade de informações disponibilizadas nesses sites de pesquisa demandam um conjunto de habilidades por parte de professores e alunos para orientar e tratar os dados coletados, no sentido de possibilitar uma aprendizagem significativa a partir da construção de conhecimentos. É preciso ter cuidado para não se perder na teia de informações disponíveis e conseguir fazer as relações necessárias e possíveis que só um pensamento complexo é capaz de fazer.

Encontrar o que se procura e descobrir as facetas agregadas a cada descoberta requer conhecimento da máquina e dos mecanismos de busca, domínio da linguagem específica da área a ser pesquisada, assim como conhecimento de idioma. (...)

Fundamentado nessas habilidades e competências, o navegar pela tela de um computador agilizará as comunicações globais e a obtenção de informações e serviços. Sem as condições para o seu uso, esse instrumento cultural, quando utilizado com esse fim, trará frustrações e poderá facilmente ser transformado numa biblioteca de Babel, ou seja, num emaranhado de informações supérfluas (FRAGOSO e BLATTMANN, 2003, p. 17).

As autoras referem-se a habilidades técnicas de busca e localização das informações, que os alunos nem sempre conseguem fazer eficientemente. Além disso, na falta de habilidades para analisar, refletir e reconstruir os alunos, muitas vezes, copiam textos inteiros da Internet, assim como copiavam antes de livros e enciclopédias. O plágio é o dilema da contemporaneidade quando a originalidade parece afundar na rede de possibilidades de burlar as regras. São tantas informações e espaços de divulgação que numa simples busca sobre um tema qualquer pode-se encontrar milhares de referências.

Essa possibilidade causa uma sensação de que tanta coisa já foi dita que não há mais nada para se dizer, portanto, não haverá problema em copiar, já que a cópia é algo praticamente institucionalizado. Sendo assim, é necessário compreender de que forma podemos realizar uma pesquisa de conteúdos numa perspectiva de construção de conhecimentos, superando a perspectiva de reprodução de informações, geralmente praticada na escola tradicional. 


\section{A PESQUISA DE CONTEÚdOS EM ESTRUTURA DE REDE: UMA METODOLOGIA QUE PRIVILEGIA A CONSTRUÇÃO DO CONHECIMENTO}

A metodologia de pesquisa de conteúdos aqui proposta busca que o aluno possa construir seu próprio conhecimento acerca de um determinado tema, conceito, conteúdo, através de uma orientação sistemática e estruturada proporcionada pelo professor, apresentando um conjunto de habilidades que o aluno deve mobilizar e de princípios para orientar sua ação de pesquisa de conteúdos. O professor deve orientar seus alunos para esses princípios e habilidades, de forma que o mesmo tenha clareza de como se constitui sua aprendizagem. Essa construção deve ser acompanhada e apoiada pelo professor, que media as ações dos alunos para que eles consigam atingir seus objetivos e realizar as atividades necessárias. No ato da pesquisa mobilizamos diversas habilidades articuladamente, não de forma linear, mas de forma complexa e inter-relacionadas.

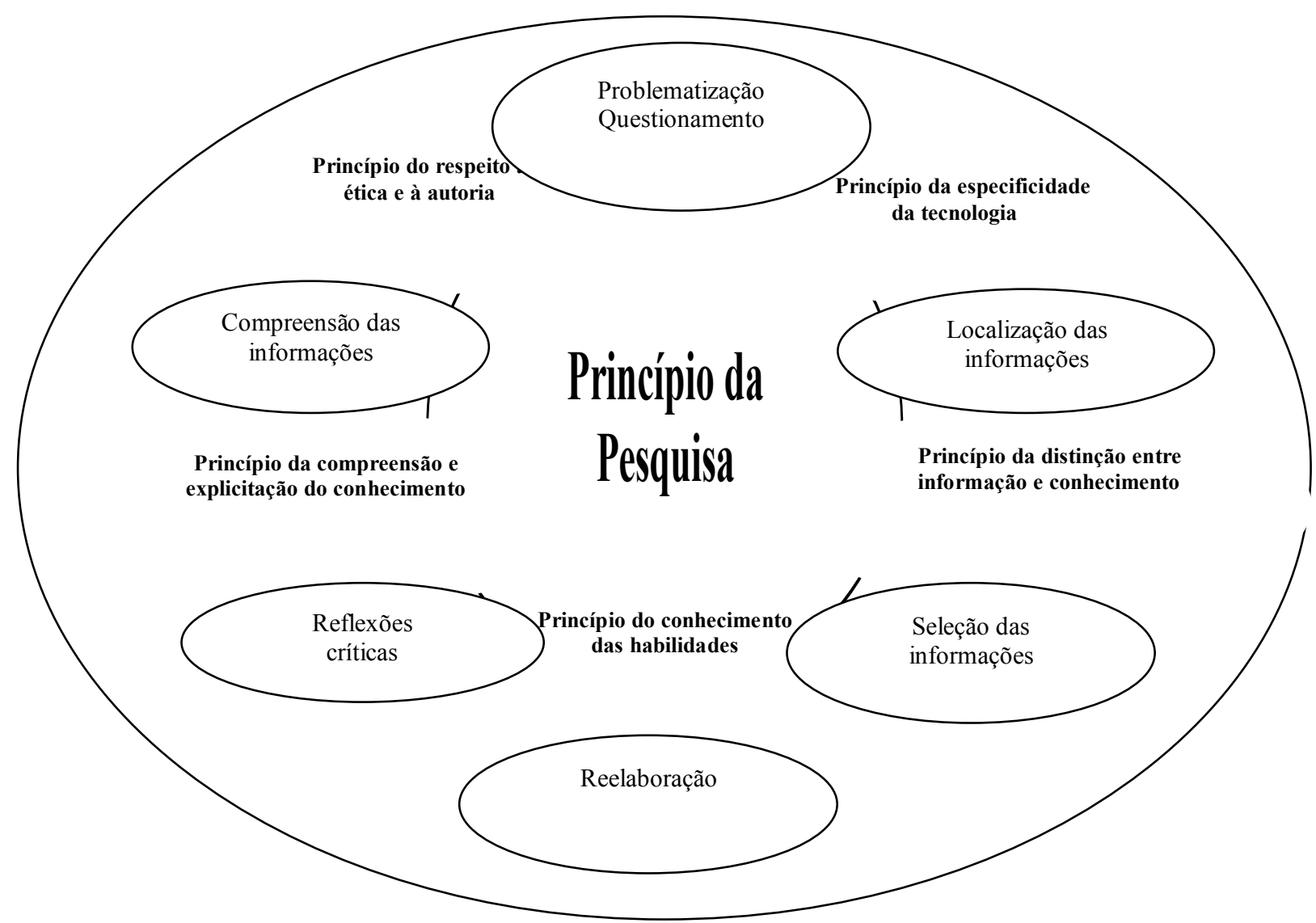

Figura 01 - Representação da pesquisa de conteúdos em estrutura de rede, suas habilidades e princípios 
Na figura 01 podemos visualizar as habilidades e princípios que identificamos como necessários para realização de uma pesquisa de conteúdos que considere a construção de conhecimentos. Acreditamos que a proposta de pesquisa de conteúdos em estrutura de rede pode proporcionar aprendizagens significativas, se levar em consideração a pesquisa enquanto processo e os princípios e habilidades que devem ser mobilizados durante esse processo.

Dessa forma, tentaremos expressar, na figura acima, tais princípios e habilidades de maneira que nos permita visualizar melhor dentro de uma mesma situação - a situação da pesquisa de conteúdos. Os princípios são as teorizações que dão sentido às habilidades e as completam, não especificamente a uma ou a outra. Ou seja, é preciso considerar os princípios para poder mobilizar as habilidades adequadamente e de forma a realização de uma pesquisa de conteúdos de forma que represente a construção do conhecimento de quem pesquisa.

As habilidades que o aluno deve mobilizar para realizar uma pesquisa de conteúdos são as seguintes:

O questionamento é necessário para estimular o aluno a inquirir sobre o objetivo da pesquisa, ressaltando a curiosidade do mesmo sobre o tema. Além disso, os questionamentos podem servir como orientadores da busca, de modo que o aluno não se perca em sua pesquisa.

Ao provocar questionamentos o professor está auxiliando seu aluno "a problematizar os significados por ele atribuídos ao conteúdo em questão e a refletir sobre a fragilidade de verdades até então inquestionáveis. Assim, o estudante pode avançar em direção à modificação e/ou ampliação de suas idéias" (LIMA, 2003, p. 94/95), dando conta assim, da aprendizagem por construção. É importante, pois, que o professor estimule a curiosidade do aluno através da problematização do que se quer aprender e que essa problematização gere questionamentos que sejam importantes e interessantes de serem respondidos. É interessante que o professor incentive seus alunos a criarem uma lista de questões a serem respondidas sobre a temática que se vai pesquisar. Essas questões podem (e devem) ser reavaliadas no processo da pesquisa. Elas orientam, como já dissemos, as escolhas dos alunos sobre as informações a serem coletadas.

A localização das informações está relacionada a capacidade que o usuário tem de localizar informações de acordo com as características da fonte utilizada para a pesquisa de conteúdos. $\mathrm{Na}$ Internet é preciso conhecer o menu principal e os ícones do navegador, suas funções, que são as ferramentas disponíveis para localizar a informação. É muito importante ter clareza do que se quer e o objetivo da busca. Também é necessário ter cuidado para não se desviar do objetivo por conta da 
enorme quantidade de conteúdos envolventes que a Internet oferece e, até mesmo pela falta de organização linear, característico do ambiente virtual.

O professor pode sugerir sites, mas deve deixar o aluno buscar novos caminhos. Mas também devese orientar o aluno para anotar o percurso (sites), concentrar-se em seu objetivo, sem necessariamente ficar cego para a riqueza dos diversos materiais que irão surgir, mas sem se desviar das questões que deve responder.

A seleção das informações refere-se à classificação do material coletado segundo a importância para a definição do conteúdo a ser pesquisado e, também, quanto à extrapolação deste para os detalhes que enriqueçam a pesquisa e até mesmo excedam o conteúdo, ampliando as informações sobre o mesmo, sem, no entanto, se desviar do objetivo da pesquisa. $\mathrm{O}$ aluno define o que é mais ou menos relevante para sua pesquisa, até mesmo informações que são apenas uma curiosidade para ilustrar a pesquisa. Nesse momento, as anotações feitas durante a localização das informações serão imprescindíveis para essa classificação.

A compreensão das informações refere-se à construção de significados que ocorre em função de um determinado dado ou nova informação. É preciso que se leve em consideração a influência dos elementos não lingüísticos como imagens e sons para a compreensão do conteúdo e também para o processo de interpretação.

Quando nos deparamos com uma informação ou fato novo precisamos criar uma representação dele. Se precisarmos daquela informação num momento próximo, nós a encontraremos rapidamente, pois ela ainda se encontra na zona de atenção que ativamos ao nos deparamos com ela. Entretanto, se precisarmos daquela informação posteriormente ativaremos elementos mnésicos, que são processos de associação daquilo que já memorizamos. É impossível ativar todos os nós mnésicos em um só momento, pois nossos recursos de memória são limitados. Sempre que procurarmos uma informação em nossa memória ativaremos primeiramente os fatos atuais até chegar onde queremos encontrar a informação. Entretanto, para isso são necessárias duas condições: "primeiro, uma representação do fato que buscamos deve ter sido conservada. Segundo, deve existir um caminho de associações possíveis que leve a esta representação" (LÉVY, 1993, p. 79). Para isso realizamos diversas elaborações cognitivas.

A reflexão crítica é a individualização dos significados compreendidos, isto é, o que o sujeito, a partir dos conhecimentos que possui, das associações que estabelece entre estes conhecimentos e as novas informações identificadas no texto no momento da compreensão, percebe como relevante para o objetivo da pesquisa, passa a envolver-se com eles e a valorar tais conhecimentos. 
Concordando, discordando, argumentando com o autor, com o texto. Posicionando-se, criticando e propondo outras formas de analisar determinado conteúdo ou fenômeno.

Geralmente, quando um professor solicita uma pesquisa escolar ele avisa aos seus alunos que os mesmos devem refletir criticamente sobre os dados de sua pesquisa. Entretanto, nós, professores, muitas vezes, não ensinamos nossos alunos a serem críticos, a argumentarem, a questionarem. Nesse momento, o professor deve oferecer espaço para que os alunos se questionem sobre os resultados encontrados, que gerem hipóteses e argumentos sobre as informações que selecionaram, que se posicionem.

A reelaboração é o processo pelo qual o sujeito irá reconstruir o conteúdo pesquisado, em um produto cultural que possa ser socializado, imprimindo nele, suas impressões, conclusões, compreensões e argumentações, levantando também novos questionamentos.

Os princípios que orientam a mobilização das habilidades são os seguintes:

O Princípio da Pesquisa refere-se à compreensão do que seja pesquisa de conteúdos. Não se pode realizar pesquisa sem compreender o que ela é. A pesquisa não é uma simples coleta de dados como nos acostumamos a realizar no Ensino Fundamental e Médio e também no Ensino Superior. Pesquisa não é apenas ler o que vários autores dizem e escrever com nossas próprias palavras.

Pesquisa é um processo que mobiliza diversas habilidades para identificar o que se quer saber, para localizar e selecionar as informações pertinentes, interpretar, refletir e se posicionar diante das informações obtidas, argumentando e propondo novas formas de compreensão, construindo assim, o nosso próprio conhecimento. Consideramos fundamental que alunos e professores tenham essa compreensão para que o processo de pesquisa seja vivido em sua plenitude.

O Princípio da distinção e relação entre os conceitos de informação e conhecimento refere-se a compreensão de que o que está disponível na Web, nos livros, revistas, etc, trata-se de informação para nós, que, ao compreendermos e interpretarmos essas informações, nos apropriamos delas e as relacionamos com o conjunto de informações e conhecimentos que possuímos em nossa estrutura cognitiva.

Como coloca Carvalho (1998) nossos esquemas cognitivos são a representação da realidade e do conhecimento que temos. Um esquema contém uma rede de conceitos que se inter-relacionam, isto é, os esquemas são holísticos. "Os esquemas são estruturas de dados para representar conceitos gerais armazenados na memória, como objetos, situações, acontecimentos, seqüências de acontecimentos, ações e seqüências de ações" (CARVALHO, 1998, p. 11).

Portanto, assim como afirma Bonilla (2005), a informação é apenas um estágio do conhecimento. 
À informação que provém do exterior são acrescentadas as informações que o sujeito possui em seu interior, aquelas relacionadas com suas experiências anteriores, produzindose um processamento de outro nível, de forma que o produto adquire outras características significativas e efetivas, distintas da original. A esse processo de atribuição de significado às informações denomina-se conhecimento (p. 19).

Dessa forma, podemos compreender melhor a importância de se conhecer os saberes prévios dos alunos de forma a que o professor possa estabelecer estratégias de relações, comparações e conclusões para que seus alunos aprendam significativamente. Para que haja essa atribuição de sentidos é preciso considerar o contexto geral em que estamos inseridos e não apenas a situação específica. Assim, conseguiremos desenvolver um pensamento complexo, conforme nos orienta Morin (2002).

O Princípio do respeito à ética e à autoria. De acordo com Demo (1997) é muito difícil termos idéias completamente novas, porém, estamos falando de idéias próprias, novo conhecimento para o sujeito aprendiz e não para a humanidade. Os professores devem estimular nos alunos a capacidade de expressar suas idéias e opiniões, a capacidade de argumentar e propor. $\mathrm{O}$ aluno tem que aprender a ser autor, ator, sujeito e não apenas leitor e objeto.

Os relatórios dos exames nacionais e internacionais (BRASIL/MEC/INEP, 2003) mostram que ainda há um grande caminho a percorrer para fazermos de nossos alunos leitores compreensivos e interpretativos. Devemos, entretanto, junto à capacidade compreensiva desenvolver a reflexão crítica, argumentativa e propositiva. Só assim teremos cidadãos mais ativos e participativos.

Com capacidade de argumentação e proposição nossos alunos não terão necessidade de copiar o argumento do outro, poderão pensar e criar por conta própria. E, mesmo em um ambiente como a Web, que nos faz ter a impressão de que tudo já foi dito não nos sentiremos atraídos pela pequenez dos desvios fáceis (FREIRE, 1996), pois teremos a necessidade de dizer o que pensamos e sabemos. O Princípio da especificidade da tecnologia está relacionado a necessidade de se conhecer a estrutura e organização do tipo de fonte em que se está pesquisando. A Web, especificamente, tem uma estrutura muito diferente da que estamos acostumados. Ela não é linear, ao contrário, é cheia de nós e links, permitindo e possibilitando caminhos diferentes para as mesmas buscas. Essa compreensão do ambiente em que se dá a pesquisa (Ciberespaço) e do material em que se pesquisa (hipertexto) é uma especificidade fundamental que precisamos ter clareza e consciência. É preciso saber navegar no ciberespaço e compreender as relações entre os nós dos hipertextos. É necessário que o usuário construa uma técnica de leitura adequada às suas próprias características cognitivas e organizativas (MACHADO et al, 2000; XAVIER, 2005). 
O Princípio da compreensão e explicitação do conhecimento deve-se a importância do professor se interessar e permitir que o aluno exponha suas opiniões para que ele possa definir as estratégias de ensino que serão necessárias para atender os objetivos da aprendizagem dos alunos, de forma a desenvolver a pesquisa como princípio educativo. É necessário que o aluno tenha consciência do seu saber e suas necessidades. Essa consciência acontece quando é possível explicitar o que se sabe e se reflete sobre o que ainda se precisa saber.

Os alunos não devem ter receio de expor seus conhecimentos, suas dúvidas, seus questionamentos. Assim, se instaura na sala de aula, um clima de cumplicidade e respeito às idéias dos outros, além da compreensão de que, para aprendermos precisamos interagir com o outro e com seus saberes.

O Princípio do conhecimento das habilidades a serem mobilizadas: a pesquisa de conteúdos em estrutura de rede. As habilidades por si só nem os princípios isolados são suficientes para que os alunos elaborem seu conhecimento e o expressem num texto lógico, coerente, com argumentação e proposições. É necessário, portanto, que além de discutir com os alunos sobre os princípios acima elencados, o professor também explicite sobre as habilidades que os alunos devem mobilizar para uma construção de conhecimentos significativa.

\section{CONSIDERAÇÕES FINAIS}

A pesquisa é uma situação didática muito rica e, sendo utilizada como princípio educativo (DEMO, 1999, 2002), pode contribuir para que o processo de ensino e aprendizagem seja mais significativo e produtivo para alunos e professores. Entretanto, para que isso ocorra efetivamente é necessário rever não apenas as práticas que temos dos processos de ensinar e aprender. É importante compreender nossas simples rotinas como parte de um sistema educacional complexo e influenciado por variáveis diversas e, muitas vezes, imprevisíveis, mas também, variáveis concretas e com as quais, muitas vezes, nos identificamos e nos entregamos. Por isso, Freire (1985), dialogando com Faundez afirma:

Por isso é que venho investindo, a teu lado, desde o primeiro diálogo nosso, numa pedagogia da radical pergunta. E esta pedagogia, vivida na escola ou na luta política, é substantivamente democrática e, por isso mesmo, antiautoritária, jamais espontaneísta ou liberal-conservadora. No fundo, uma pedagogia em cuja prática não há lugar para a dicotomia entre sentir o fato e apreender a sua razão de ser. A sua crítica à escola tradicional não se esgota nas questões técnicas e metodológicas, nas relações importantes 
educadoreducando, mas se estende à crítica do próprio sistema capitalista (FREIRE e FAUNDEZ, 1985, p. 56-57).

E, nessa defesa por uma pedagogia da pergunta Freire e Faundez (op cit) afirmam que a origem do conhecimento está na pergunta e que o professor deve criar o hábito, em si mesmo e em seus alunos de perguntar e perguntar-se, de 'espantar-se'. Para Freire (1996) a escola mata essa curiosidade e virtude da criança que é perguntar, porquê, como, aonde, quem... A escola deve, portanto, resgatar urgentemente essa curiosidade, essa sede de saber, para podermos continuar a fazer perguntas e tentar respondê-las, pois, assim, estaremos buscando soluções. E, com a busca de soluções poderemos ter um mundo melhor, uma escola melhor, pessoas melhores.

Precisamos aprender a perguntar, a argumentar e a propor. Podemos dizer que o aluno copia porque não sabe pesquisar, se tomarmos pesquisa como um processo que requer habilidades para problematização, questionamento, seleção e tratamento das informações, com capacidade reflexiva, crítica, argumentativa e também escritora. Para isso é preciso ter um pensamento complexo, compreendendo "o tecido de acontecimentos, ações, interações, retroações, determinações, acasos, que constituem nosso mundo fenemônico" (MORIN, 2005, p. 13). Considerar essa complexidade para a pesquisa de conteúdos, portanto, é considerar a sua renovação. Ou seja, compreendê-la como um processo de construção de conhecimentos e não como simples acumulação de informações.

\section{BIBLIOGRAFIA}

BARREIRO, Cristhianny Bento. Questionamento sistemático: alicerce na reconstrução dos conhecimentos. In: MORAES, Roque; LIMA, Valderez Marina do Rosário (Orgs.). Pesquisa em sala de aula: tendências para a educação em novos tempos. 2. ed. Porto Alegre: EDIPUCRS, 2004.

BELLUZZO, Regina C. B. Competências na era digital: desafios tangíveis para bibliotecários e educadores. ETD - Educação Telemática Digital. Campinas, v. 6, n. 2, p. 27-42, jan/2005.

BONILLA, Maria Helena Silveira. Escola aprendente: para além da sociedade da informação. Rio de Janeiro: Quartet, 2005.

BRASIL/INEP/MEC. Pisa 2003: relatório nacional. INEP, Ministério da Educação. Brasília, 2003. CAMPELLO, Bernadete Santos et al. A Internet na Pesquisa Escolar: um panorama do uso da Web por alunos do ensino fundamental, 2002. Disponível em

$<$ http://www.biblioestudantes.hpg.ig.com.br/tecnologia.htm> Acesso em 25/04/2004. 
CAMPELLO, B. S. . A competência informacional na educação para o Século XXI. In: Bernadete Campello. (Org.). A biblioteca escolar: temas para uma prática pedagógica. Belo Horizonte: Autêntica, 2002.

CAMPELLO, et al. A biblioteca escolar: temas para uma prática pedagógica. Belo Horizonte: Autêntica, 2002.

CARVALHO, Maria da Conceição. Internet e pesquisa escolar. In: CAMPELLO, et al. A biblioteca escolar: temas para uma prática pedagógica. Belo Horizonte: Autêntica, 2002.

CARVALHO, Ana Amélia C.C.A.S. Os ambientes hipermédia estruturados segundo a Teoria da Flexibilidade Cognitiva: a importância dos "Comentários Temáticos" e das "Travessias Temáticas" na transferência do conhecimentos para novas situações. Tese de Doutoramento. Instituto de Educação e Psicologia. Universidade do Minho, Portugal, 1998.

DEMO, Pedro. Pesquisa e construção de conhecimento: metodologia científica no caminho de Habermas. Rio de Janeiro: Tempo Brasileiro, 1997.

. Pesquisa: princípio científico e educativo. 6a Ed. São Paulo: Cortez, 1999.

. Educar pela pesquisa. 5a Ed. Campinas, São Paulo: Autores Associados, 2002.

FRAGOSO, Graça Maria e BLATTMANN, Ursula. O zapear na informação. In: FRAGOSO, Graça Maria e BLATTMANN, Ursula (Orgs.) O zapear e a informação em bibliotecas e na Internet. Belo Horizonte: Autêntica, 2003.

FREIRE, Paulo e FAUNDEZ, Antônio. Por uma pedagogia da pergunta. Rio de Janeiro: Paz e Terra, 1985.

FREIRE, Paulo. Pedagogia da Autonomia: saberes necessários à prática educativa. São Paulo: Paz e Terra, 1996.

LÉVY, Pierre. As tecnologias da inteligência: o futuro do pensamento na era da informática. São Paulo: Editora 34, 1993.

LIMA, Valderez Marina do Rosário. A sala de aula do educar pela pesquisa: uma história a ser contada. In: Educação, Ano XXVI, nº 51, Porto Alegre, outubro 2003.

MACHADO, A. M. N.; QUARTIERO, E. M.; BIANCHETTI, L. O Hipertexto com e sem o computador: novas estratégias e recursos de uma prática antiga. In: Revista Nexos: Estudos em Comunicação e Educação, Marília SP, v. 6, 2000.

MORAES, Roque et al. Pesquisa em sala de aula: fundamentos e pressupostos. In: MORAES, Roque; LIMA, Valderez Marina do Rosário (Orgs.). Pesquisa em sala de aula: tendências para a educação em novos tempos. 2. ed. Porto Alegre: EDIPUCRS, 2004.

MORIN, Edgar. A cabeça bem-feita: repensar a reforma, reformar o pensamento. $6^{\text {a }}$ edição. Rio de Janeiro: Bertrand Brasil, 2002. 
. Introdução ao pensamento complexo. Porto Alegre: Sulina, 2005.

MORO, Eliane L. da Silva, et al. A integração dos atores - alunos, educadores e bibliotecários na realização da pesquisa escolar através da utilização das tecnologias de informação e de comunicação. Grupo de Estudos em biblioteca escolar. Escola de Ciência daInformação da UFMG. Disponível em $<$ http://www.eci.ufmg.br/gebe/downloads/304.pdf $>$ Acesso em 22 de outubro de 2006.

PELLANDA, Nize Maria Campos. O sentido profundo da solidariedade. In: PELLANDA, Nize Maria Campos; SCHLÜNZEN, Elisa Tomoe Mariya; SCHLÜNZEN JUNIOR, Klaus (Orgs).

Inclusão digital: tecendo redes afetivas/cognitivas. Rio de Janeiro: DP\&A, 2005.

RAMOS, Maurivan Güntzel. Educar pela pesquisa é educar para a argumentação. In: MORAES, Roque; LIMA, Valderez Marina do Rosário (Orgs.). Pesquisa em sala de aula: tendências para a educação em novos tempos. 2. ed. Porto Alegre: EDIPUCRS, 2004.

SILVA, Waldeck Carneiro da. Miséria da Biblioteca escolar. São Paulo: Cortez, 1995.

XAVIER, Antônio Carlos. Leitura, texto e hipertexto. In: MARCUSCHI, L.A.; XAVIER, A.C. Hipertexto e gêneros digitais: novas formas de construção do sentido. 2 a edição. Rio de Janeiro: Lucerna, 2005. 